\title{
CHANGES IN THE ARMY NURSE CORPS
}

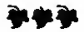

\section{CHANGES IN THE ARMY NURSE CORPS RECORDED IN THE SURGEON-GENERAL'S OFFICE FOR THE MONTH ENDING FEBRUARY 6, Ig02.}

Armistead, Amanda J., transferred from the Santa Mesa Hospital, near Manila, to duty at the First Reserve Hospital, Manila, P. I.

Bauer, Christiana M., transferred from the Santa Mesa Hospital, near Manila, to duty at the First Reserve Hospital, Manila, P. I.

Colcleugh, Ada, transferred from First Reserve Hospital, Manila, P. I., to duty on transport Grant en route to United States. Arrived in San Francisco January 21 and assigned temporarily to duty at General Hospital, Presidio.

Conners, Katherine, transferred from First Reserve Hospital, Manila, to duty on Grant en route to the United States. Arrived in San Francisco January 21 and assigned temporarily to duty at General Hospital, Presidio.

Cox, Sara M., transferred from the Santa Mesa Hospital, near Manila, to the Convalescent Hospital, Corregidor Island, P. I.

Fisher, Julia Helen, whose appointment was reported last month, was obliged to withdraw at the last moment.

Flick, Lucile E. S., transferred from the United States Army General HoBpital, Presidio, San Francisco, to duty on transport Kilpatrick en route to the Philippines.

Graham, Catherine B., transferred from the Santa Mesa Hospital, near Manila, to the Convalescent Hospital, Corregidor Island, P. I.

Hanson, Bernice E., appointed January 8 and assigned to duty at the United States Army General Hospital, Presidio, San Francisco, Cal.

Harrison, Mary A., transferred from the Santa Mesa Hospital, near Manila, to duty at the First Reserve Hospital, Manila, P. I.

Hasemeyer, Augusta D., formerly nurse at Military Hospital, Vigan, P. I., assigned to duty as chief nurse at that hospital December 21, 1901.

Kennedy, Emma L., arrived in Manila December 2, 1901, and reported at First Reserve Hospital for temporary duty, awaiting assignment.

Lane, Effie, transferred from the Santa Mesa Hospital, near Manila, to duty on the Grant en route to the United States. Arrived in San Francisco January 21 and assigned to duty at General Hospital, Presidio.

Laughlin, Mary C., arrived in Manila December 2, 1901, and reported at the First Reserve Hespital for temporary duty, awaiting assignment.

Livingston, Mrs. Tessie, transferred from the Santa Mesa Hospital, near Manila, to duty at the First Reserve Hospital, Manila, P. I.

Macaulay, Margaret, transferred from the Santa Mesa Hospital, near Manila, to duty on the Grant en route to the United States. Arrived in San Francisco January 2l; on leave, awaiting orders.

Mann, Emilyn P., transferred from the First Reserve Hospital, Manila, to 
duty on the Grant en route to the United States. Arrived in San Francisco January 21. Under orders to return to the Philippines.

McGary, Margaret, appointed January 8 and assigned to duty at the United States Army General Hospital, Presidio, San Francisco, Cal.

McKeever, Melvina, formerly chief nurse at Military Hospital, Iloilo, P. I., discharged.

Morgan, Irene A., transferred from the United States Army General Hospital, Presidio, San Francisco, to duty on the Kilpatrick en route to the Philippines.

Ostien, Mary F., transferred from the United States Arny General Hospital, Presidio, San Francisco, to duty on the Kilpatrick en route to the Philippines.

Plummer, Samantha C., transferred from the Santa Mesa Hospital, near Manila, to duty at the First Reserve Hospital, Manila, P. I.

Redecker, Henrietta L., transferred from the First Reserve Hospital, Manila, to duty on the Kilpatrick en route to the United States. Arrived in San Francisco January 0, and assigned to duty at General Hospital, Presidio, for three months.

Rice, Margaret Van Schaick, transferred from the Santa Mesa Hospital, near Manila, to the First Reserve Hospital, Manila, P. I.

Richmond, Edith L., transferred from the Santa Mesa Hospital, ncar Manila, to the First Reserve Hospital, Manila, P. I.

Thacher, Clara, transferred from the First Rescrve Hospital, Manila, to the Military Hospital, Iloilo, P. I., and assigned to duty as chief nurse.

Thomas, Elizabeth D., transferred from the Santa Mesa Hospital, near Manila, to duty at the First Rescrve Hospital, Manila, P. I.

Tipping, Susie, appointed January 8 and assigned to duty at the United States Army General Hospital, Presidio, San Francisco, Cal.

Whelpton, Sarah, transferred from duty as chief nurse at Santa Mesa Hospital, near Manila, to duty as nurse at the First Reserve Hospital, Manila, P. I.

Wiedmann, Barbara, transferred from the Santa Mesa Hospital, near Manila, to duty on the Kilpatrick en route to the United States. Arrived in San Francisco January 9 and assigned to duty at the General Hospital, Presidio, for three months.

Wilson, Sibbie, transferred from the First Reserve Hospital, Manila, to duty on the Warren en route to the United States. Arrived in San Francisco January 10 and assigned to duty at the General Hospital, Presidio, for three months.

Woods, Julia E., transferred from the United States Army General Hospital, Presidio, San Francisco, to duty on the Kilpatrick en route to the Philippines.

Young, Agnes G., transferred from the Santa Mesa Hospital, ncar Manila, to duty at the First Reserve Hospital, Manila, P. I.

Young, Ann B., transferred from the United States Army General Hospital, Presidio, San Francisco, to duty on the Kilpatrick en route to the Philippines.

Wilson, Genevieve, transferred from the United States Army General Hospital, Presidio, San Francisco, Cal., to duty at the United States General Hospital, Fort Bayard, N. M.

Zink, Josephine, formerly on duty at the Convalescent Hospital, Corregidor Island, P. I., discharged in Manila. 